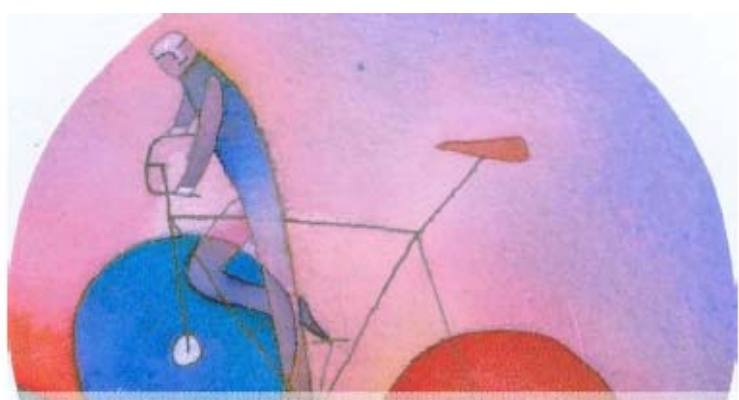

\title{
IEFE
}

Centre for Research on Energy and Environmental Economics and Policy

Working Paper Series - ISSN 1973-0381

The Demographic Transition and the Ecological Transition: Enriching the Environmental Kuznets Curve Hypothesis

\author{
Marzio Galeotti, Alessandro Lanza and \\ Maria Carla Ludovica Piccoli
}

Working Paper n. 44

July 2011

\begin{abstract}
IEFE - The Center for Research on Energy and Environmental Economics and Policy at Bocconi University via Guglielmo Röntgen, 1 - 20136 Milano tel. 02.5836.3820 - fax 02.5836.3890

www.iefe.unibocconi.it - iefe@unibocconi.it
\end{abstract}

This paper can be downloaded at www.iefe.unibocconi.it The opinions expressed herein do not necessarily reflect the position of IEFE-Bocconi. 
Electronic copy available at: http://ssrn.com/abstract=1922594 


\title{
The Demographic Transition and the Ecological Transition: Enriching the Environmental Kuznets Curve Hypothesis
}

\author{
by \\ Marzio Galeotti \\ (University of Milan and IEFE-Bocconi University) \\ Alessandro Lanza \\ (Eni Corporate University S.p.A.) \\ Maria Carla Ludovica Piccoli \\ (Enel S.p.A.)
}

\begin{abstract}
The impact of population growth on the environment is an issue that is highly debated yet comparatively under-researched empirically. This is true despite a vast number of published articles on the link between population and environmental changes speculating on the sign of the environmentpopulation elasticity. Although the issue can ultimately only be settled at the empirical level, the above contributions have been largely speculative. It was only in the mid-1990s that population was accounted for in the empirical work on the relationship between environmental quality/degradation and income within the framework of the "Environmental Kuznets Curve" (EKC) hypothesis. While empirical EKC investigations have provided a useful contribution to the issue, a further important step can be made. Population in the EKC hypothesis is not treated like income but it serves, so to speak, just as a normalizing variable. As it turns out, however, also for population can we formulate a hypothetical behavior of its evolution over time vis-à-vis income, that can be accommodated within an EKC framework. This is the Demographic Transition. With the exception of Baldwin (1995) none of the studies mentioned so far have investigated the nexus between pollution, environmental degradation, and income within the conceptual framework of the two transitions: the demographic and the ecological one. The present paper represents the first econometric analysis of Demographic and Ecological Transitions. We incorporate the former into the EKC framework, thus obtaining an "enriched" EKC hypothesis. Very long time series for 17 OECD countries in the case of $\mathrm{CO}_{2}$ emissions support our empirical approach.
\end{abstract}

June 2011

Keywords: Environment, Growth, $\mathrm{CO}_{2}$ Emissions, Population JEL Classification: O13, Q30, J00, C12, C22

This study does not necessarily reflect the views of Eni Corporate University S.p.A. or of Enel S.p.A. We thank Walther Galvalisi for excellent research assistantship. Paper to be presented at the 2010 International Energy Workshop, Stockholm June 21-23, and at the Fourth World Congress of Environmental and Resource Economists, Montreal June 28-July 2, 2010.

Corresponding author: Professor Marzio Galeotti, Dipartimento di Scienze Economiche Statistiche e Aziendali, Università di Milano, via Conservatorio 7, I-20122 Milano, Italy. E-mail: marzio.galeotti@unimi.it. 


\section{The Demographic Transition and the Ecological Transition: Enriching the Environmental Kuznets Curve Hypothesis}

\section{Introduction}

A well known view holds that Sustainable Development is guaranteed by a flow of services generated by a stock of (physical, human, natural, and social) capital. To guarantee sustainability that flow of services must not decline over time, which in turn implies that the capital stock must be preserved. Because natural capital cannot be easily substituted with the other capital types, natural capital itself must not decline. This explains why the quality of the environment, within which global climate change is a prominent example, has traditionally played such an important role in the sustainability debate. In general, while progress in technology has the ability of expanding the capital basis over time, population growth may exert an increasing negative pressure upon it. Indeed, it could be argued that one of the fundamental causes of increasing pollution lies in population growth, in that more people consume natural resources and dump waste in the environment. Roughly put, poverty makes people and people make pollution.

A time-honoured tool that effectively brings together the main ingredients of the environmental problem is the Kaya identity (Kaya, 1990). According to the formula, emissions (or, more generally, some measure of environmental degradation) can be decomposed into the product of four components: carbon intensity, energy intensity, per capita income, and population. Emissions are affected by, on the one hand, technological forces inducing changes in carbon and energy intensities, and socio-economic forces inducing changes in incomes and population, on the other. If we look at the actual data, one key fact is that the technological forces do not succeed in offsetting the socio-economic forces, so that emissions in the aggregate grow. This is made apparent by the WGIII contribution to the IPCC AR4, which notes that "the effect on global emissions of the decrease in global energy intensity (-33\%) during 1970 to 2004 has been smaller than the combined effect of global income growth $(77 \%)$ and global population growth $(69 \%)$ with the result of increasing energy-related $\mathrm{CO}_{2}$ emissions" (IPCC, 2007). ${ }^{1}$

\footnotetext{
${ }^{1}$ Using symbols, and referring to $\mathrm{CO}_{2}$ emissions as our measure of pollution, the Kaya identity reads as follows: $\mathrm{CO}_{2}=\left(\mathrm{CO}_{2} / E\right) *(E / Y) *(Y / P) * P$
} 
Considering the rates of change of the variables in the Kaya decomposition we see that emissions, say of $\mathrm{CO}_{2}$, can slow their pace when one or more components reduce their speed of growth. The decomposition is instructive in that it also shows how one critical sustainability goal is to increase per capita incomes especially of poor regions: ceteris paribus, this is a factor of increase in $\mathrm{CO}_{2}$ emissions. This implies that climate change can be lessened if the growth of population slows down, and if technological change brings about energy savings and energy efficiency improvements, as well as an increased decarbonisation of economic systems. These considerations suggest a role for policy. We could try to severe the link low income - large population by implementing appropriate birth control measures. This is admittedly complex a task but it could play a role at the international bargaining table. We could also try to modify the relationship between per capita income growth and pollution increase. This could be done with the help of technology leading to an increase of emission abatement, but also with changes in current modes of production and consumption.

Although the Kaya device is very useful in highlighting the link between pollution, income, technology, and population, it rests on an identity: it is therefore void of any behavioural or predictive content.

The impact of population growth on the environment is an issue that is highly debated yet comparatively under-researched empirically. This is true despite a vast number of published articles on the link between population and environmental changes have appeared within the last few decades (Lutz, Prskawet, and Sanderson, 2002). Particularly lacking are systematic empirical studies comprehensively examining the population-environment relationship at the global level. Ever since Malthus, Ricardo and Mill, scientists have been concerned that rising population would deplete agricultural and other natural resources and significantly contribute to environmental degradation (Ehrlich, 1968; Meadows, Meadows, Zahn, and Milling, 1972). However, this view is not shared by all. Neo-Malthusians like Ehrlich and Holdren (1971), Kahn, Brown, and Martel (1976) and Ehrlich and Ehrlich (1990) regarded population growth as a significant, if not the major, factor behind environmental degradation. Boserup (1965) and later Simon (1981, 1996) argued instead that a rising

where $E$ stands for energy, $Y$ income, and $P$ population. More succinctly, hiding the role of energy and denoting by $\mathrm{CO}_{2} / Y$ the degree of carbonization of an economy we can rewrite the above expression as: $\mathrm{CO}_{2}=\left(\mathrm{CO}_{2} / \mathrm{Y}\right) *(\mathrm{Y} / \mathrm{P}) * \mathrm{P}$

Using lowercase letters to denote growth rates we further have: $\mathrm{CO}_{2}=\left(\mathrm{co}_{2} / y\right)+y / p+p$ 
population needs not lead to more depletion as high population densities provide fertile ground for institutional and technological innovations to overcome any apparent resource constraint. Commoner, Corr, Stamler (1971) instead maintained that environmental degradation is not largely due to population growth. Finally, the so-called cornucopians regard human ingenuity as the 'ultimate resource'. Since more people mean that problems are tackled by more brains, a larger population renders more likely the scientific, technological and institutional progress necessary to overcome any apparent environmental problem.

Although the issue can ultimately only be settled at the empirical level, the above contributions have been largely speculative. It was only in the mid-1990s that population was accounted for in the empirical work on the relationship between environmental quality/degradation and income.

To analyze the above-mentioned debate, effectively summarized in Panayotou (2000), we can write environmental degradation $E D$ as a function of population $P$ and a vector of other variables, most notably income $Y$, so that:

(1) $\quad E D=f(P, Y)$

The pessimists' or Neo-Malthusians' argument is that the population elasticity is at least one if not higher, so that an increase in population leads to a proportional or more than proportional increase in environmental degradation. The optimists or cornucopians, on the other hand, believe that the population elasticity is certainly below one, unlikely to be statistically different from zero and possibly even negative. Which perspective is closer to reality is an empirical question. Empirical studies which explicitly examine the link between population and pollution in a systematic quantitative manner are very few in number: a partial list includes Cramer (1998, 2002), Cramer and Cheney (2000), Dietz and Rosa (1994, 1997), York, Rosa and Dietz (2003), Shi (2003), Cole and Neumayer (2006). If we take the function $f$ to be linear homogenous in its arguments we may write it in per-capita terms, so that:

$$
E D / P=g(Y / P)
$$


Equation (2) can be recognized as the prototypical relationship at the basis of the "Environmental Kuznets Curve" (EKC) hypothesis (see Galeotti, 2007, among several other survey papers). If we look at (1) we see that GDP and population are the two forces that affect the level of pollution in the empirical reduced-form relationship describing the EKC. However, population does not play an independent role relative to income; indeed the EKC is invariably stated in per capita terms, to capture the idea that two countries with the same GDP but with different number of inhabitants will not in general produce the same amount of pollution. From an econometric viewpoint specifying variables in per capita terms corrects for the heteroskedasticity that would arise when data relative to different countries are considered at the same time.

Note that, relative to (1), expression (2) in principle contains a testable assumption, as it imposes linear homogeneity of relationship linking, say, emissions $(E)$, income $(Y)$ and population $(P)$. This is the hypothesis the EKC literature has typically made. One stream of contributions, however, has questioned whether per capita GDP does account for all factors influencing polluting emissions. These papers have noted that other variables are likely to play an independent role in the relationship. Examples often made are the share of manufacturing GDP relative to total GDP, the share of imports/exports over GDP, institutional variables, and the like (see, among many others, Panayotou, 2000). Among these variables sometimes also population or other demographic variables are included. One way to assess whether population plays a role in addition to income is to test for homogeneity of (1) by looking at the statistical significance of the population regressor in:

$$
E D / P=h(Y / P, P)
$$

Some EKC studies have included population density as one of many determinants of pollution concentrations, but have tended to find mixed results: see Grossman and Krueger (1995), Panayotou (1997), Hilton and Levinson (1998), Lantz and Feng (2006), and MartinezZarzoso, Bengochea-Morancho and Morales-Lase (2007). One relevant recent example is Cole and Neumayer (2003). This paper discusses at length the importance of aspects related 
to the dynamics of population and the impact on the environment. In the end the authors provide estimated results for sulfur and carbon dioxide emissions of EKC-type relationships. In particular, they relate emissions to per capita GDP (interestingly enough, the marginal effect of this variable on emissions does not vary further with income), to a couple of variables capturing the composition of output and to several population-related variables. The authors find confirmation of the importance of demographic effects for emission levels and conclude that the treatment of population in EKC analyses ought to be richer than usually posited in the literature.

While the above study (and the other cited papers) provide a useful contribution to the issue, a further important step can be made in the analysis of the population-environment nexus. It is important to recall that the EKC is a hypothesis, a conceptual explanation of the relationship between income and pollution and a prediction about the shape of that relationship. Population in the EKC hypothesis is not treated like income but it serves, so to speak, just as a normalizing variable.

As it turns out, however, also for population can we formulate a hypothetical behavior of its evolution over time vis-à-vis income, that can be accommodated within an EKC framework. In so doing we obtain a complex relationship linking pollution levels to GDP and to population, involving both levels and growth rates. We reinterpret the above contribution as imposing parametric restrictions in our more general relationship which can the be viewed as an enriched EKC relationship.

\section{Ecological Transition and Demographic Transition}

According to the EKC hypothesis per-capita pollution (emissions for instance), in relation with per capita income, goes through different stages. They can be understood by referring to "incipient" pollution, that is generated absent any abatement, and by abatement brought about by deliberate policies and measures. According to the "Ecological Transition" (ET) incipient pollution start low from low per-capita income levels, when the economy is still in an agricultural phase, but it then grows in the industrial phase and eventually declines when society is rich and services prevail. In addition, as per capita income increases pollution abatement increases, because of a greater importance of environmental policies and technological progress. The actual observed abatement is the difference between incipient 
pollution and abatement activities: this implies that per capita pollution relative to per capita income has an inverted-U shape. This behavior is typical of Environmental Kuznets Curves.

Another important transition has to do with population. According to the theory of the Demographic Transition (DT) the evolution of population goes through three phases. ${ }^{2}$ Initially, when income is low and the economy is in a preindustrial state, both birth and death rates are high: cultural reasons and no birth control measures keep birth rates high while the plight of people and little progress in medical science keep death rates high. Population growth is consequently low. As incomes grow the situation improves. In the second, industrial phase, while death rates decline birth rates remain initially high, so that population growth is strong. In the final phase, as per capita incomes further increase, both rates are reduced and population growth slows down. These (and more sophisticated) considerations lead to represent population growth vis-à-vis per capita income by means, again, of an inverted-U shape, like a "Demographic Kuznets Curve" (DKC) (see Bartlett, 1997; Daly and Erlich 1992; Pimentel 1996).

With the exception of Baldwin (1995) none of the studies mentioned so far has investigated the nexus pollution, environmental degradation, and income within the conceptual framework of the two transitions: the demographic and the ecological one. ${ }^{3}$

At this point we may want to examine the two transitions jointly, also looking at the current positioning of the world population. The data show that more then $50 \%$ of world population lies in the second phase of the demographic transition and at a stage of the ecological transition where per capita incomes are still low (see Figure 1). From a sustainability point of view the problem is how to take most of the world population to higher income levels without causing deep environmental degradation. The implications for policy here are apparent. It remains, however, as a preliminary step to understand which and how important the interrelations between the two transitions are, the implications one has for the other, possibly adopting a regional perspective, typically between rich and poor countries. A

\footnotetext{
${ }^{2}$ This theory was originally expounded by the French demographer Landry in 1934.

${ }^{3}$ See An and Jeon (2006) for an empirical study on demographic change and economic growth. Aznar-Marquez and Tamarit (2005) instead present an endogenous growth model with pollution and abatement for which they obtain the socially optimal solution. They find that the rate of growth depends negatively on the weight of environmental care in utility and positively on the population growth rate. In addition, they find a trade-off between growth and environmental quality beyond which an environmental Kuznets curve is derived in the long term. This one emerges from the implications of the demographic transition for the rate of population growth, and the accompanying variation in the willingness to pay for environmental quality as the economy develops.
} 
second important aspect to recall is that inverted-U EKCs may not hold for all pollutants and that the evidence in this respect is mixed. This holds in principle also for the demographic transition. A third caveat refers to the fact the EKCs are in general effective ways to summarize ex-post correlations, but they cannot be used to draw policy implications such as, say, unconditional and accelerated economic growth. Analogous considerations could be made for unconditional population growth!

The above caveats notwithstanding, it is useful to re-examine on empirical grounds the nexus between environment, population and income. We do not intend to provide here and empirical investigation of the DT or of the DKC hypothesis. Rather, we take it for granted and incorporate it into the EKC framework. We can gain insights into the nexus between the variables under study from such an enriched EKC relationship.

Because DT is a very long term phenomenon we use very long historical time series for which measures of environmental degradation are available. As it turns out, data for emissions of carbon dioxide (million metric tons) are available from the Oak Ridge National Laboratory's CDIAC from 1871 through 2005. These data are made available by ENERDATA together with GDP expressed in PPP 2000 millions USD and population in thousand people. ${ }^{4}$ Because of the length of the sample the number of countries considered has to be restricted to 17 OECD nations. These are: The country are: Australia, Austria, Belgium, Canada, Denmark, Finland, France, Germany, Italy, Japan, Netherlands, New Zealand (data here start from 1878), Norway, Sweden, Switzerland, UK, USA. The examined variables are expressed in log form and estimation is performed for each country using ordinary least squares (OLS).

\section{The Role of Population in EKC Empirical Analysis}

Before incorporating the DT we would like to investigate the role of population in the standard EKC framework. The general formulation starts from a third order loglinear expansion of (1):

\footnotetext{
${ }^{4}$ Historical data on population and GDP were originally developed in three books by Maddison (1995, 2001, 2003). Historical data on carbon dioxide emissions are from Boden, Marland, and Andres (2009).
} 
(4) $\log E=\alpha_{0}+\alpha_{1} \log Y+\alpha_{2}(\log Y)^{2}+\alpha_{3}(\log Y)^{3}+\beta_{1} \log P+\beta_{2}(\log P)^{2}+\beta_{3}(\log P)^{3}$

We allow for a cubic term because there is empirical evidence in the literature of $\mathrm{N}$ shaped EKC relationships for some pollutants. Note that we ignore interaction terms between $P$ and $Y$ which should in principle be included in (4). The traditional EKC specification can be derived from (4) under the following homogeneity restrictions $\beta_{1}=1-\alpha_{1} ; \beta_{2}=-\alpha_{2} ; \beta_{3}=-\alpha_{3}$, so that:

$$
\log (E / P)=\alpha_{0}+\alpha_{1} \log (Y / P)+\alpha_{2}[\log (Y / P)]^{2}+\alpha_{3}[\log (Y / P)]^{3}
$$

A test of the homogeneity hypothesis rests upon estimating (4) and carrying out a F test of the above restrictions. Alternatively, one can estimate (5) augmented with a population term, or:

$$
\log (E / P)=\alpha_{0}+\alpha_{1} \log (Y / P)+\alpha_{2}[\log (Y / P)]^{2}+\alpha_{3}[\log (Y / P)]^{3}+\gamma \log P
$$

and simply test the null hypothesis $\gamma=0$. Cole and Neumayer (2006) propose a relationship similar to (6):

$$
\log E=\alpha_{0}+\alpha_{1} \log (Y / P)+\gamma_{2} \log P+\gamma_{3}(\log P)^{2}
$$

where we have omitted other demographic variables considered by the authors. This formulation can be seen as a special case of (4) but some arbitrary parametric restrictions are introduced. As a matter of fact, the authors state that they tried also a square GDP term but it did not turn out to be significant. In addition, note that emissions are not in per capita terms. The regression actually estimated is in first differences. 
In Tables 1 and 2 we start by estimating the standard quadratic and cubic representations of the EKC hypothesis as in (5). It can be seen that the cubic income term is statistically significant for a number of countries, but not all of them (7 cases out of 17). The relationship appears to be N-shaped for Canada, Japan, New Zealand, Norway, Switzerland, and the US. In all other cases the evidence is consistent with an inverted-U EKC.

The next step is to ask whether the implied homogeneity of the relationship is supported by the data. Tables 3 and 4 present the evidence. It is interesting to note that the additional population regressor of the estimated model (6) turns out not to be significant only in a handful of cases: Austria, Canada, France, New Zealand, and Sweden. The evidence thus shows that there is more to population than in the standard Environmental Kuznets Curve formulation. Further investigation of the role of population and population growth in the environment-income nexus is therefore warranted.

\section{The Empirical Implications of the Demographic Transition for EKC Analysis}

The standard EKC-type relationship in (5) is now coupled with an analytical expression summarizing the demographic transition. In keeping with (5) we generally write the DKC relationship as follows:

$$
\Delta \log P=\delta_{0}+\delta_{1} \log (Y / P)+\delta_{2}[\log (Y / P)]^{2}+\delta_{3} \log [\log (Y / P)]^{3}
$$

Our simple strategy is to manipulate (8) and substitute the result into (5) in order to obtain an EKC that accounts for both environmental and demographic transitions. To this end solve (8) for cubic per capita GDP:

$$
[\log (Y / P)]^{3}=\delta_{3}^{-1}\left\{\Delta \log P-\delta_{0}-\delta_{1} \log (Y / P)-\delta_{2}[\log (Y / P)]^{2}\right\}
$$

Substitute (9) into (5) we get: 


$$
\log (E / P)=\theta_{0}+\theta_{1} \log (Y / P)+\theta_{2} \log [(Y / P)]^{2}+\varphi \Delta \log P
$$

We straightforwardly obtain an EKC-type relationship with emissions and income in per capita terms but augmented with the rate of population growth. This is an interesting empirical implication. Notice that starting form third order relationships we have arrived at a "standard" quadratic formulation for the EKC albeit augmented by an additional explanatory variable. We would expect in general $\theta_{1}>0$ and $\theta_{2}<0$ while the sign of $\varphi$ cannot be predicted a priori. Indeed, the parametric restrictions underlying (10) show that:

$$
\begin{aligned}
& \theta_{1}=\alpha_{1}-\delta_{1} \frac{\alpha_{3}}{\delta_{3}}=\alpha_{1}-\delta_{1} \varphi \\
& \theta_{2}=\alpha_{2}-\delta_{2} \frac{\alpha_{3}}{\delta_{3}}=\alpha_{2}-\delta_{2} \varphi \\
& \varphi=\frac{\alpha_{3}}{\delta_{3}}
\end{aligned}
$$

Note that the sign of (13) affects the sign of the other income coefficients, so that no coefficient is a priori unambiguously signed.

The DT explanation of the behavior of population over time generated a DKC that has in principle an inverted-U shape. In fact, there is no theoretical reason why the DKC should be represented by a third order polynomial. The empirical evidence of the previous section also shows that we cannot reject the assumption of an inverted- $U$ shape for $\mathrm{CO}_{2}$ emissions for a high number of countries. We can therefore limit attention to quadratic polynomials both for (5) and (8) and go through the same analytical steps to obtain a linear-in-per capita income relationship:

$$
\log (E / P)=\theta_{0}+\theta_{1} \log (Y / P)+\varphi \Delta \log P
$$


where:

$$
\theta_{1}=\alpha_{1}-\delta_{1} \frac{\alpha_{2}}{\delta_{2}}=\alpha_{1}-\delta_{1} \varphi
$$

$$
\varphi=\frac{\alpha_{2}}{\delta_{2}}
$$

Here predicting the sign is easier as far as $\varphi>0$ is concerned, but we cannot exclude that $\theta_{1}$ be of any sign, although economic sense suggests it to be positive.

The relationships (10) and (14) are shown to provide testable implications that account for the impact of the demographic transition in the environmental transition. We therefore turn to the empirical evidence. Estimated results for the linear model (14) are presented in Table 5 and for the quadratic model in Table 6.

Both specification lend strong support to the enriched version of the EKC hypothesis, that is to the idea of empirically accounting for both the ecological and the demographic transitions when analyzing the nexus between environment, income, and population. This is confirmed by the rate of growth of population that enters as a significant explanatory variable for all countries in at least one specification of tables 5 and 6.

If we look at the results of the quadratic specification in particular, form Table 6 we note that the quadratic per capita income term is always significant and negatively signed, as expected, with exception of New Zealand. The coefficient of population growth is generally positive, as expected. From (16) we see that if the two transitions can indeed be represented by inverted-U quadratic relationships, then the coefficient has to be positive. This is indeed the case for all countries in Table 5. Less obvious is the case of cubic specifications, although from (13) we could reasonably expect the cubic terms of EKC and DKC to be similarly signed. This implies a positive coefficient for population growth also in the specification of Table 6. With the notable exceptions of Sweden and the U.S. that is precisely what happens. 


\section{Conclusions}

Although the role of population is accounted for in empirical investigations of the Environmental Kuznets Curve hypothesis, there is more to it. Population does not merely play a normalizing role for the income level of a country. Rather, countries undergo over time a demographic transition as their economic development progresses, in a manner similar to the ecological transition described by the EKC.

Although the discussion of the impact of population growth on the quality of the environment is not new, Richard Baldwin (1995)'s insight has been to bring together demographic and environmental transitions within the analysis of the nexus between environment-income-population. It has been on that basis that he could conclude that economic growth is necessary for sustainability, and that demographic policies such as birth control measures can help toward that end.

Baldwin's policy implications have been based on very valuable speculative considerations. What in a sense was lacking was statistical support. This is what the present paper has purported to do. We have provided an econometric analysis of Demographic and Ecological Transitions. Although they could be investigated separately, we have incorporated the insights from the former into the latter to obtain an "enriched" Environmental Kuznets Curve hypothesis. This specification interestingly shows that the rate of population growth enters as an extra term the standard EKC formulation.

Very long time series (1871-2005) for seventeen OECD countries in the case of $\mathrm{CO}_{2}$ emissions were used and the estimation results were shown to lend strong support our empirical approach in the case of almost all countries considered. 


\section{References}

An, C. and S. Jeon (2006), "Demographic Change and Economic Growth: An Inverted-U Shape Relationship", Economics Letters, 92, 447-45.

Aznar-Marquez, J. and J.R. Tamarit (2005), "Demographic Transition, Environmental Concern and the Kuznets Curve“, Département des Sciences Economiques de l'Université catholique de Louvain, Discussion Paper N. 2005-1.

Baldwin, R., (1995), "Does sustainability require growth?", in I. Goldin and L.A. Winters (eds.), The Economics of Sustainable Development, Paris: OECD, 51-78.

Bartlett A. A. (1997), "Reflection on Sustainability, Population Growth, and the Environment - Revisited", Renewable Resources Journal, 15.

Boden, T.A., G. Marland, and R.J. Andres (2009), "Global, Regional, and National FossilFuel $\mathrm{CO}_{2}$ Emissions", Carbon Dioxide Information Analysis Center, Oak Ridge National Laboratory, U.S. Department of Energy, Oak Ridge, Tenn., U.S.A. doi 10.3334/CDIAC/00001.

Boserup, E. (1965), The Conditions of Agricultural Growth, London: George Allen and Urwin.

Boserup, E. (1981), Population and Technological Change: A Study of Long-Term Trends, Chicago: University of Chicago Press.

Cole, M.A. and E. Neumayer (2006), "Examining the Impact of Demographic Factors on Air Pollution", Population and Environment, 26, 5-21.

Commoner, B., M. Corr. and P.J. Stamler (1971), "The Causes of Pollution,” Environment, $13,2-19$.

Cramer, C.J. (1998), "Population Growth and Air Quality in California", Demography, 35, $45-56$.

Cramer, C.J. (2002), "Population Growth and Local Air Pollution: Methods, Models, and Results," Population and Environment, 28, 22-52.

Cramer, C.J. and Cheney (2000), "Lost in the Ozone: Population Growth and Ozone in California", Population and Environment, 21, 315-337.

Daly, G.C. and P.R. Ehrlich (1992), "Population, Sustainability and Earth's Carrying Capacity", Biosciences 42, 761-771.

Dietz, T. and E.A. Rosa (1994), "Rethinking the Environmental Impacts of Population, Affluence, and Technology", Human Ecology Review, 1, 277-300.

Dietz, T. and E.A. Rosa (1997), "Effects of Population and Affluence on $\mathrm{CO}_{2}$ Emissions", Proceedings of the National Academy of Sciences USA, 94, 175-179.

Ehrlich, P.R. (1968), The Population Bomb, New York: Sierra Club-Ballantine.

Ehrlich, P.R. and A.H. Ehrlich (1990), The Population Explosion, London: Hutchinson.

Ehrlich, P.R. and J.P. Holdren (1971), "Impact of Population Growth", Science, 171, 12121217. 
Galeotti M. (2007), "Economic Growth and the Quality of the Environment: Taking Stock". Environment, Development and Sustainability, 9, 427-454.

Grossman, G.M, and A.B. Krueger (1995), "Economic growth and the environment," Quarterly Journal of Economics, 110, 353-377.

Hilton, F.G.H. and A. Levinson (1998), "Factoring the Environmental Kuznets Curve: Evidence from Automotive Lead Emissions," Journal of Environmental Economics and Management, 35, 126-141.

IPCC (2007), "Summary for Policymakers", IPCC Fourth Assessment Report, Working Group III.

Kahn, H., W. Brown, and L. Martel (1976), The Next 200 Years, New York: William Morrow.

Kaya, Y. (1990), "Impact of Carbon Dioxide Emission Control on GNP Growth: Interpretation of Proposed Scenarios", paper presented to the IPCC Energy and Industry Subgroup, Response Strategies Working Group, Paris.

Landry, A. (1934), La Révolution Démographique, Paris: Sirey.

Lantz, V. and Q. Feng (2006), "Assessing Income, Population, and Technology Impacts on $\mathrm{CO}_{2}$ Emissions in Canada: Where's the EKC?”, Ecological Economics 57, 229-238.

Lutz, W., A. Prskawetz, and W.C. Sanderson (2002), "Introduction," Population and Environment, 28, 1-21.

Maddison, A. (1995), Monitoring the World Economy 1820-1992, Paris: OECD Development Centre.

Maddison, A. (2001), The World Economy: A Millennial Perspective, Paris: OECD Development Centre.

Maddison, A. (2003), The World Economy: Historical Statistics, Paris: OECD Development Centre.

Martínez-Zarzoso, I., A. Bengochea-Morancho, and R. Morales-Lage (2007), "The Impact of Population on $\mathrm{CO} 2$ Emissions: Evidence from European Countries", Environment and Resource Economics 38, 497-512.

Meadows, D., D. Meadows, E. Zahn, and P. Milling (1972), The Limits to Growth, New York: Universe Books.

Panayotou, T. (1997), "Demystifying the Environmental Kuznets Curve: Turning a Black Box into a Policy Tool," Environment and Development Economics, 2, 465-484.

Panayotou, T. (2000), "Population and Environment", Center for International Development at Harvard University Working Paper n. 54.

Pimentel D. et al. (1996), "Impact of Population Growth on Food Supplies and Environment", presented at the AAAS Annual Meeting, Baltimore, MD.

Shi, A. (2003), "The Impact of Population Pressure on Global Carbon Dioxide Emissions, 1975-1996: Evidence from Pooled Cross-country Data", Ecological Economics 44, 29-42.

Simon, J.L. (1981), The Ultimate Resource, Princeton: Princeton University Press.

Simon, J.L. (1996), The ultimate resource 2, Princeton: Princeton University Press. 
York, R., E.A. Rosa, and T. Dietz (2003), "STIRPAT, IPAT and ImPACT: Analytic Tools for Unpacking the Driving Forces of Environmental Impacts," Ecological Economics, 46, $351-365$. 
Figure 1: The Ecological and the Demographic Transitions Together

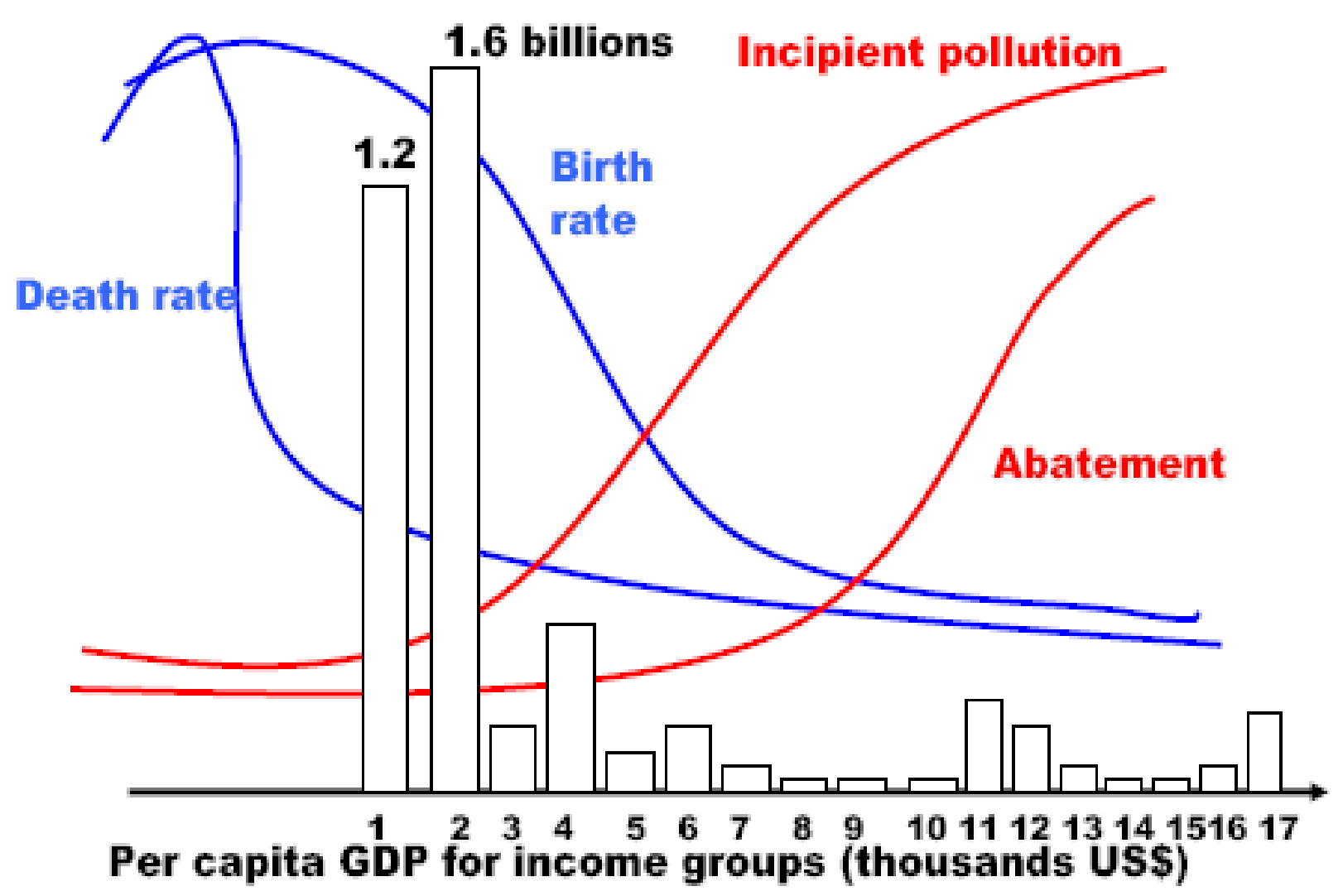

Source: Baldwin (1995) 
Table 1: Homogenous Quadratic EKC Specification

\begin{tabular}{|c|c|c|c|c|c|c|c|c|}
\hline \multicolumn{9}{|c|}{ Model 1, dependent variable: LCO2PC.OLS estimation. } \\
\hline MODEL 1 & Constant & \multicolumn{3}{|c|}{ LGDPPC } & \multicolumn{3}{|c|}{ LGDPPC2 } & \\
\hline COUNTRY & Coefficient & Coefficient & T-test & p-value & Coefficient & T-test & $\mathrm{p}$-value & R-squared \\
\hline Australia & $-9,062$ & 6,964 & 8,46 & $<0,00001 * * *$ & $-1,146$ & $-1,15$ & $<0,00001 * * *$ & 0,80 \\
\hline Austria & 40,413 & 27,676 & 3,93 & $0,00014 * * *$ & $-3,368$ & $-2,05$ & $0,04285 * *$ & 0,64 \\
\hline Belgium & $-2,374$ & 2,812 & 16,17 & $<0,00001 * * *$ & $-0,552$ & $-14,30$ & $<0,00001 * * *$ & 0,81 \\
\hline Canada & $-63,598$ & 13,924 & 20,09 & $<0,00001 * * *$ & $-0,744$ & $-18,75$ & $<0,00001 * * *$ & 0,93 \\
\hline Denmark & $-3,919$ & 3,136 & 30,07 & $<0,00001 * * *$ & $-0,492$ & $-20,24$ & $<0,00001 * * *$ & 0,98 \\
\hline Finland & $-5,750$ & 4,023 & 20,37 & $<0,00001 * * *$ & $-0,579$ & $-10,53$ & $<0,00001 * * *$ & 0,95 \\
\hline France & $-2,454$ & 2,492 & 28,16 & $<0,00001 * * *$ & $-0,487$ & $-22,53$ & $<0,00001 * * *$ & 0,95 \\
\hline Germany & $-1,816$ & 2,650 & 12,01 & $<0,00001 * * *$ & $-0,529$ & $-10,61$ & $<0,00001 * * *$ & 0,68 \\
\hline Japan & $-3,241$ & 3,118 & 24,87 & $<0,00001 * * *$ & $-0,590$ & $-15,47$ & $<0,00001 * * *$ & 0,94 \\
\hline Italy & $-4,083$ & 2,272 & 10,86 & $<0,00001 * * *$ & $-0,227$ & $-4,11$ & $0,00007 * * *$ & 18,94 \\
\hline Netherlands & $-3,944$ & 3,277 & 18,62 & $<0,00001 * * *$ & $-0,551$ & $-14,10$ & $<0,00001 * * *$ & 19,91 \\
\hline New Zeland & $-2,428$ & 1,679 & 4,12 & $0,00007 * * *$ & $-0,211$ & $-2,15$ & $0,03355 * *$ & 0,79 \\
\hline Norway & $-2,158$ & 1,470 & 9,70 & $<0,00001 * * *$ & $-0,176$ & $-4,74$ & $<0,00001 * * *$ & 14,43 \\
\hline Sweden & $-3,657$ & 3,136 & 14,98 & $<0,00001 * * *$ & $-0,570$ & $-10,79$ & $<0,00001 * * *$ & 0,88 \\
\hline Switzerland & $-3,261$ & 1,641 & 5,18 & $<0,00001 * * *$ & $-0,153$ & $-2,25$ & $0,02590 * *$ & 0,84 \\
\hline UK & $-0,104$ & 1,024 & 7,82 & $<0,00001 * * *$ & $-0,220$ & $-7,83$ & $<0,00001 * * *$ & 0,32 \\
\hline USA & $-2,710$ & 3,082 & 21,31 & $<0,00001 * * *$ & $-0,535$ & $-17,34$ & $<0,00001 * * *$ & 0,91 \\
\hline
\end{tabular}

Footnotes:

(1) Dependent variable: log of carbon dioxide emissions per capita; independent variable: log of GDP per capita.

(2) T-statistics computed from robust standard errors in round brackets.

(3) Sample period: 1871-2005. 
Table 2: Homogenous Cubic EKC Specification

\begin{tabular}{|c|c|c|c|c|c|c|c|c|c|c|c|}
\hline \multicolumn{12}{|c|}{ Model 3, dependent variable: LCO2PC.OLS estimation. } \\
\hline MODEL 3 & Constant & \multicolumn{3}{|c|}{ LGDPPC } & \multicolumn{3}{|c|}{ LGDPPC2 } & \multicolumn{3}{|c|}{ LGDPPC3 } & \\
\hline COUNTRY & Coefficient & Coefficient & T-test & p-value & Coefficient & T-test & p-value & Coefficient & T-test & p-value & R-squared \\
\hline Australia & $-17,220$ & 17,93 & 3,13 & $0,00219 * * *$ & $-5,910$ & $-2,39$ & $0,01827 * *$ & 0,670 & 1,93 & $0,05555 *$ & 0,81 \\
\hline Austria & 18,780 & 63,86 & 2,16 & $0,03302 * *$ & $-21,980$ & $-1,48$ & 0,14248 & 2,960 & 1,26 & 0,21095 & 0,65 \\
\hline Belgium & $-2,410$ & 2,86 & 2,93 & $0,00401 * * *$ & $-0,580$ & $-1,26$ & 0,20877 & 0,003 & 0,05 & 0,95953 & 0,81 \\
\hline Canada & $-422,280$ & 139,61 & 15,28 & $<0,00001 * * *$ & $-15,360$ & $-14,47$ & $<0,00001 * * *$ & 0,560 & 13,77 & $<0,00001 * * *$ & 0,97 \\
\hline Denmark & $-3,620$ & 2,63 & 5,34 & $<0,00001 * * *$ & $-0,230$ & $-0,91$ & 0,36554 & $-0,040$ & $-1,06$ & 0,29122 & 0,98 \\
\hline Finland & $-5,610$ & 3,64 & 6,00 & $<0,00001 * * *$ & $-0,320$ & $-0,81$ & 0,41847 & $-0,050$ & $-0,67$ & 0,50360 & 0,95 \\
\hline France & $-2,360$ & 2,32 & 6,08 & $<0,00001 * * *$ & $-0,390$ & $-1,93$ & $0,05551 *$ & $-0,020$ & $-0,47$ & 0,63991 & 0,95 \\
\hline Germany & $-2,760$ & 4,16 & 3,80 & $0,00023 * * *$ & $-1,280$ & $-2,39$ & $0,01842 * *$ & 0,120 & 1,41 & 0,16149 & 0,69 \\
\hline Japan & $-3,500$ & 4,74 & 27,64 & $<0,00001 * * *$ & $-2,140$ & $-15,03$ & $<0,00001 * * *$ & 0,350 & 11,08 & $<0,00001 * * *$ & 0,97 \\
\hline Italy & $-3,430$ & 0,82 & 1,15 & 0,25258 & 0,690 & 1,59 & 0,11444 & $-0,170$ & $-2,13$ & $0,03496 * *$ & 0,93 \\
\hline Netherlands & $-3,910$ & 3,23 & 3,26 & $0,00142 * * *$ & $-0,530$ & $-1,15$ & 0,25114 & $-0,003$ & $-0,05$ & 0,96121 & 0,94 \\
\hline New Zeland & $-10,510$ & 14,35 & 5,51 & $<0,00001 * * *$ & $-6,600$ & $-5,07$ & $<0,00001 * * *$ & 1,040 & 4,92 & $<0,00001 * * *$ & 0,82 \\
\hline Norway & $-3,230$ & 3,58 & 6,52 & $<0,00001 * * *$ & $-1,350$ & $-4,55$ & $0,00001 * * *$ & 0,190 & 3,98 & $0,00011 * * *$ & 0,88 \\
\hline Sweden & $-3,480$ & 2,79 & 3,31 & $0,00121 * * *$ & $-0,380$ & $-0,82$ & 0,41636 & $-0,030$ & $-0,42$ & 0,67719 & 0,88 \\
\hline Switzerland & $-7,980$ & 8,72 & 5,51 & $<0,00001 * * *$ & $-3,480$ & $-4,75$ & $<0,00001 * * *$ & 0,490 & 4,56 & $0,00001 * * *$ & 0,86 \\
\hline UK & $-0,470$ & 1,53 & 1,71 & 0,08924 & $-0,440$ & $-1,13$ & 0,25954 & 0,030 & 0,57 & 0,56775 & 0,33 \\
\hline USA & $-6,570$ & 8,72 & 17,26 & $<0,00001 * * *$ & $-3,110$ & $-13,70$ & $<0,00001 * * *$ & 0,370 & 11,40 & $<0,00001 * * *$ & 0,96 \\
\hline
\end{tabular}


Table 3: Non-homogenous Quadratic EKC Specification

\begin{tabular}{|c|c|c|c|c|c|c|c|c|c|c|c|}
\hline \multicolumn{12}{|c|}{ Model 2, dependent variable: LCO2PC.OLS estimation. } \\
\hline MODEL 2 & Constant & \multicolumn{3}{|c|}{ LGDPPC } & \multicolumn{3}{|c|}{ LGDPPC2 } & \multicolumn{3}{|c|}{ LPOP } & \\
\hline COUNTRY & Coefficient & Coefficient & T-test & $p$-value & Coefficient & T-test & $p$-value & Coefficient & T-test & $p$-value & R-squared \\
\hline Australia & $-14,860$ & 0,710 & 1,38 & 0,17029 & $-0,220$ & $-2,27$ & $0,02502 * *$ & 1,660 & 19,98 & $<0,00001 * * *$ & 0,95 \\
\hline Austria & 60,230 & 28,820 & 3,41 & $0,00086 * * *$ & $-3,550$ & $-1,96$ & $0,05244 *$ & $-2,410$ & $-0,25$ & 0,80393 & 0,64 \\
\hline Belgium & 3,220 & 3,820 & 12,81 & $<0,00001 * * *$ & $-0,730$ & $-12,71$ & $<0,00001 * * *$ & $-0,760$ & $-4,04$ & $0,00009 * * *$ & 0,84 \\
\hline Canada & $-63,690$ & 14,030 & 18,62 & $<0,00001 * * *$ & $-0,750$ & $-18,35$ & $<0,00001 * * *$ & $-0,060$ & $-0,37$ & 0,71269 & 0,9 \\
\hline Denmark & 1,350 & 4,080 & 10,42 & $<0,00001 * * *$ & $-0,640$ & $-10,11$ & $<0,00001 * * *$ & $-0,790$ & $-2,5$ & $0,01368 * *$ & 0,9 \\
\hline Finland & 17,850 & 6,290 & 12,32 & $<0,00001 * * *$ & $-0,960$ & $-10,14$ & $<0,00001 * * *$ & $-3,170$ & $-4,75$ & $<0,00001 * * *$ & 0,9 \\
\hline France & $-13,880$ & 2,560 & 26,66 & $<0,00001 * * *$ & $-0,550$ & -13 & $<0,00001 * * *$ & 1,080 & 1,78 & $0,07701 *$ & 0,95 \\
\hline Germany & 4,520 & 3,370 & 12,46 & $<0,00001 * * *$ & $-0,630$ & $-11,95$ & $<0,00001 * * *$ & $-0,690$ & $-4,17$ & $0,00006 * * *$ & 0,72 \\
\hline Japan & $-4,270$ & 3,040 & 9,93 & $<0,00001 * * *$ & $-0,580$ & $-9,66$ & $<0,00001 * * *$ & 0,100 & 0,26 & 0,79218 & 0,92 \\
\hline Italy & 12,080 & 3,300 & 7,61 & $<0,00001 * * *$ & $-0,400$ & $-4,78$ & $<0,00001 * * *$ & $-1,620$ & $-2,69$ & $0,00802 * * *$ & 0,93 \\
\hline Netherlands & $-5,480$ & 2,810 & 12,34 & $<0,00001 * * *$ & $-0,480$ & $-10,94$ & $<0,00001 * * *$ & 0,240 & 3,05 & $0,00278 * * *$ & 0,9 \\
\hline New Zeland & $-3,270$ & 0,770 & 1,18 & 0,24106 & $-0,070$ & $-0,55$ & 0,58550 & 0,280 & 1,76 & $0,08146 *$ & 0,7 \\
\hline Norway & $-22,590$ & $-0,370$ & $-0,68$ & 0,50014 & 0,070 & 0,89 & 0,37502 & 2,840 & 3,49 & $0,00067 * * *$ & 0,8 \\
\hline Sweden & $-3,620$ & 3,140 & 6,42 & $<0,00001 * * *$ & $-0,570$ & $-7,62$ & $<0,00001 * * *$ & $-0,005$ & $-0,01$ & 0,99590 & 0,88 \\
\hline Switzerland & $-24,640$ & 0,320 & 0,77 & 0,44214 & $-0,120$ & $-1,87$ & $0,06338 *$ & 2,870 & 4,42 & $0,00002 * * *$ & 0,8 \\
\hline UK & 4,780 & 1,890 & 7,02 & $<0,00001 * * *$ & $-0,370$ & $-7,55$ & $<0,00001 * * *$ & $-0,560$ & $-3,64$ & $0,00040 * * *$ & 0,3 \\
\hline USA & $-8,190$ & 2,170 & 8,24 & $<0,00001 * * *$ & $-0,430$ & $-11,02$ & $<0,00001 * * *$ & 0,590 & 4,06 & $0,00009 * * *$ & $0,9 c$ \\
\hline
\end{tabular}


Table 4: Non-homogenous Cubic EKC Specification

\begin{tabular}{|c|c|c|c|c|c|c|c|c|c|c|c|c|c|c|c|c|c|c|}
\hline \multicolumn{19}{|c|}{ Model 4, dependent variable: LCO2PC.OLS estimation. } \\
\hline MODEL 4 & Constant & \multicolumn{4}{|c|}{ LGDPPC } & \multicolumn{4}{|c|}{ LGDPPC2 } & \multicolumn{4}{|c|}{ LGDPPC3 } & \multicolumn{4}{|c|}{ LPOP } & \\
\hline COUNTRY & Coefficient & Coefficient & T-test & $\mathrm{p}$-value & & Coefficient & T-test & $p$-value & & Coefficient & T-test & p-value & & Coefficient & T-test & $\mathrm{p}$-value & & RSQ. \\
\hline Australia & $-22,160$ & 10,57 & 3,84 & 0,00019 & $* * *$ & $-4,510$ & $-3,82$ & 0,00021 & $* * *$ & 0,600 & 3,64 & 0,00039 & $* * *$ & 1,660 & 20,85 & $<0,00001$ & $* * *$ & 0,96 \\
\hline Austria & 70,200 & 73,11 & 2,23 & 0,02771 & . & $-25,620$ & $0-1,61$ & 0,10985 & & 3,460 & 1,40 & 0,16523 & & $-6,690$ & $-0,66$ & 0,50986 & & 0,65 \\
\hline Belgium & 3,750 & 7,27 & 5,80 & $<0,00001$ & $* * *$ & $-2,230$ & ( $-4,19$ & 0,00005 & $* * *$ & 0,210 & 2,83 & 0,00541 & $* * *$ & $-1,100$ & $-5,02$ & $<0,00001$ & $* * *$ & 0,84 \\
\hline Canada & $-423,620$ & 140 & 15,25 & $<0,00001$ & $* * *$ & $-15,410$ & $0-14,44$ & $<0,00001$ & $* * *$ & 0,570 & 13,74 & $<0,00001$ & $* * *$ & 0,070 & 0,62 & 0,53367 & & 0,97 \\
\hline Denmark & 1,580 & 3,59 & 5,79 & $<0,00001$ & $* * *$ & $-0,390$ & $-1,52$ & 0,13094 & & $-0,040$ & $-1,03$ & 0,30711 & & $-0,790$ & $-2,48$ & 0,01456 & $* *$ & 0,98 \\
\hline Finland & 24,170 & 8,3 & 7,93 & $<0,00001$ & $* * *$ & $-1,990$ & $-4,16$ & 0,00006 & $* * *$ & 0,180 & 2,20 & 0,02999 & $* *$ & $-4,090$ & $-5,25$ & $<0,00001$ & $* * *$ & 0,96 \\
\hline France & $-13,900$ & 2,57 & 6,34 & $<0,00001$ & $* * *$ & $-0,550$ & $-2,49$ & 0,01406 & $* *$ & 0,000 & 0,01 & 0,99273 & & 1,080 & 1,71 & 0,08940 & $*$ & 0,95 \\
\hline Germany & 3,910 & 6,43 & 5,79 & $<0,00001$ & $* * *$ & $-2,100$ & $-4,02$ & 0,00010 & $* * *$ & 0,230 & 2,84 & 0,00532 & $* * *$ & $-0,820$ & $-4,90$ & $<0,00001$ & $* * *$ & 0,73 \\
\hline Japan & 4,400 & 5,42 & 18,44 & $<0,00001$ & $* * *$ & $-2,340$ & $-15,01$ & $<0,00001$ & $* * *$ & 0,370 & 11,72 & $<0,00001$ & $* * *$ & $-0,750$ & $-2,82$ & 0,00555 & $* * *$ & 0,97 \\
\hline Italy & 10,860 & 2,01 & 2,34 & 0,02096 & $* *$ & 0,370 & $0 \quad 0,82$ & 0,41184 & & $-0,140$ & $-1,74$ & 0,08357 & $*$ & $-1,440$ & $-2,39$ & 0,01842 & $* *$ & 0,93 \\
\hline Netherlands & $-5,490$ & 2,84 & 2,93 & 0,00399 & $* * *$ & $-0,490$ & $-1,11$ & 0,26918 & & 0,002 & 0,03 & 0,97979 & & 0,240 & 3,04 & 0,00289 & *** & 0,95 \\
\hline New Zeland & $-10,510$ & 14,35 & 4,68 & $<0,00001$ & $* * *$ & $-6,600$ & $-4,55$ & 0,00001 & $* * *$ & 1,040 & 4,52 & 0,00001 & $* * *$ & $-0,001$ & 0,00 & 0,99740 & & 0,82 \\
\hline Norway & $-13,890$ & 2,03 & 1,81 & 0,07305 & $*$ & $-0,910$ & $-2,22$ & 0,02847 & $* *$ & 0,140 & 2,43 & 0,01639 & $* *$ & 1,520 & 1,58 & 0,11774 & & 0,88 \\
\hline Sweden & $-5,070$ & 2,61 & 2,10 & 0,03730 & $* *$ & $-0,320$ & $-0,58$ & 0,56178 & & $-0,040$ & $-0,46$ & 0,64468 & & 0,200 & 0,20 & 0,84000 & & 0,88 \\
\hline Switzerland & $-19,950$ & 5,56 & 2,74 & 0,00698 & $* * *$ & $-2,360$ & $-2,77$ & 0,00643 & $* * *$ & 0,330 & 2,64 & 0,00940 & $* * *$ & 1,820 & 2,42 & 0,01690 & $* *$ & 0,89 \\
\hline UK & 5,500 & 5,99 & 5,03 & $<0,00001$ & $* * *$ & $-2,020$ & $-4,29$ & 0,00004 & $* * *$ & 0,220 & 3,53 & 0,00059 & $* * *$ & $-0,940$ & $-5,15$ & $<0,00001$ & $* * *$ & 0,43 \\
\hline USA & $-7,450$ & 8,35 & 12,94 & $<0,00001$ & $* * *$ & $-3,000$ & $-11,66$ & $<0,00001$ & $* * *$ & 0,360 & 10,06 & $<0,00001$ & $* * *$ & 0,110 & 0,93 & 0,35438 & & 0,96 \\
\hline
\end{tabular}


Table 5: Demographic and Ecological Transitions in the Quadratic EKC Specification

\begin{tabular}{|l|r|rr|r|rrr|r|}
\hline \multicolumn{7}{|c|}{ Model 5, dependent variable: LCO2PC.OLS estimation. } \\
\hline \multicolumn{7}{|c|}{ MODEL 5 } & Constant & \multicolumn{3}{|c|}{ DLPOP } & \multicolumn{3}{c|}{ LGDPPC } \\
\hline COUNTRY & Coefficient & Coefficient & T-test & p-value & Coefficient & T-test & p-value & R-squared \\
\hline Australia & $-2,96$ & $-3,3$ & $-1,83$ & $0,06913 *$ & 1,55 & 19,21 & $<0,00001 * * *$ & 0,75 \\
Austria & 50,27 & 513,93 & 5,55 & $<0,00001 * * *$ & 13,89 & 16,82 & $<0,00001 * * *$ & 0,7 \\
Belgium & 0,12 & 3,72 & 0,87 & 0,38421 & 0,35 & 10,98 & $<0,00001 * * *$ & 0,51 \\
Canada & $-7,65$ & 17,59 & 3,66 & $0,00037 * * *$ & 0,93 & 20,23 & $<0,00001 * * *$ & 0,76 \\
Denmark & $-2,42$ & 1,16 & 24,54 & $<0,00001 * * *$ & 28,55 & 3,23 & $0,00158 * * *$ & 0,91 \\
Finland & $-4,62$ & 2,01 & 31,09 & $<0,00001 * * *$ & 10,96 & 1 & 0,31840 & 0,91 \\
France & $-0,74$ & 0,49 & 17,84 & $<0,00001 * * *$ & 9,55 & 3,17 & $0,00191 * * *$ & 0,76 \\
Germany & 0,49 & 0,31 & 9,18 & $<0,00001 * * *$ & $-2,9$ & $-2,06$ & $0,04113 * *$ & 0,41 \\
Japan & $-3,46$ & 1,37 & 29,36 & $<0,00001 * * *$ & 78,61 & 7,29 & $<0,00001 * * *$ & 0,88 \\
Italy & $-3,98$ & 1,54 & 41,52 & $<0,00001 * * *$ & 59,16 & 6,67 & $<0,00001 * * *$ & 0,94 \\
Netherlands & $-1,83$ & 0,89 & 25,14 & $<0,00001 * * *$ & 22,31 & 3,89 & $0,00016 * * *$ & 0,87 \\
New Zeland & $-1,42$ & 0,76 & 19,31 & $<0,00001 * * *$ & $-3,01$ & $-1,5$ & 0,13709 & 0,8 \\
Norway & $-1,5$ & 0,74 & 24,05 & $<0,00001 * * *$ & $-8,99$ & $-0,98$ & 0,32821 & 0,84 \\
Sweden & $-1,81$ & 0,89 & 19,65 & $<0,00001 * * *$ & $-3,28$ & $-0,28$ & 0,78180 & 0,77 \\
Switzerland & $-2,49$ & 0,92 & 24,78 & $<0,00001 * * *$ & $-1,12$ & $-0,24$ & 0,80949 & 0,83 \\
UK & 1,04 & 0 & $-0,19$ & 0,84634 & $-1,3$ & $-0,43$ & 0,67090 & 0,63 \\
USA & 0,6 & 0,46 & 11,31 & $<0,00001 * * *$ & $-27,03$ & $-4,55$ & $0,00001 * * *$ & 0,74 \\
\hline
\end{tabular}


Table 6: Demographic and Ecological Transitions in the Cubic EKC Specification

\begin{tabular}{|c|c|c|c|c|c|c|c|c|c|c|c|}
\hline \multicolumn{12}{|c|}{ Model 6, dependent variable: LCO2PC.OLS estimation. } \\
\hline \multicolumn{2}{|c|}{ MODEL 6 Constant } & \multicolumn{3}{|r|}{ LGDPPC } & \multicolumn{3}{|c|}{ LGDPPC2 } & \multicolumn{3}{|c|}{ DLPOP } & \multirow[b]{2}{*}{ R-squared } \\
\hline COUNTRY & Coefficient & Coefficient & T-test & p-value & Coefficient & T-test & p-value & Coefficient & T-test & $p$-value & \\
\hline Australia & $-8,890$ & $-4,350$ & 8,96 & $0,00565 * * *$ & $-1,150$ & $-6,98$ & $<0,00001 * * *$ & 6,940 & $-2,82$ & $<0,00001 * * *$ & 0,82 \\
\hline Austria & 34,860 & 533,950 & 4,79 & $<0,00001 * * *$ & $-3,940$ & $-2,65$ & $0,00920 * * *$ & 30,700 & 5,88270 & $<0,00001 * * *$ & 0,71 \\
\hline Belgium & $-2,500$ & 6,860 & 16,52 & $0,00974 * * *$ & $-0,560$ & $-14,63$ & $<0,00001 * * *$ & 2,880 & 2,62 & $<0,00001 * * *$ & 0,82 \\
\hline Canada & $-63,650$ & $-4,750$ & 18,93 & 0,10111 & $-0,750$ & $-17,67$ & $* * *$ & 13,970 & $-1,65$ & $<0,00001 * * *$ & 0,93 \\
\hline Denmark & $-3,890$ & 3,110 & 29,05 & $<0,00001 * * *$ & $-0,490$ & $-18,72$ & $<0,00001 * * *$ & 0,310 & 0,06 & 0,94895 & 0,98 \\
\hline Finland & $-5,980$ & 4,090 & 20,3 & $<0,00001 * * *$ & $-0,580$ & $-10,62$ & $<0,00001 * * *$ & 16,570 & 2,07 & $0,04028 * *$ & 0,96 \\
\hline France & $-2,390$ & 2,420 & 27,2 & $<0,00001 * * *$ & 0,470 & $-21,95$ & $<0,00001 * * *$ & 3,740 & 2,66 & $0,00873 * * *$ & 0,95 \\
\hline Germany & $-1,710$ & 2,580 & 11,78 & $<0,00001 * * *$ & $-0,510$ & $-10,42$ & $<0,00001 * * *$ & $-2,460$ & $-2,37$ & $0,01912 * *$ & 0,69 \\
\hline Italy & $-4,240$ & 1,960 & 10,29 & $<0,00001 * * *$ & $-0,120$ & $-2,25$ & $<0,00001 * * *$ & 52,420 & 5,68 & $<0,00001$ & 0,94 \\
\hline Japan & $-3,320$ & 2,960 & 20,55 & $<0,00001 * * *$ & $-0,540$ & $-11,34$ & $13 * *$ & 13,250 & 1,39 & $0,16793 * * *$ & 0,94 \\
\hline Netherlands & $-3,890$ & 3,260 & 17,03 & $<0,00001 * * *$ & $-0,550$ & $-12,5$ & $<0,00001 * * *$ & $-2,120$ & $-0,49$ & 0,62490 & 0,94 \\
\hline New Zeland & $-1,960$ & 1,300 & 3,39 & $0,00093 * * *$ & $-0,130$ & $-1,42$ & 0,15759 & $-2,770$ & $-1,38$ & 0,17125 & 0,8 \\
\hline Norway & $-2,000$ & 1,450 & 9,68 & $<0,00001 * * *$ & $-0,180$ & $-4,79$ & $<0,00001 * * *$ & $-15,410$ & $-1,8$ & $0,07432 *$ & 0,87 \\
\hline Sweden & $-3,540$ & 3,220 & 15,4 & $<0,00001 * * *$ & $-60,000$ & $-11,28$ & $<0,00001 * * *$ & $-26,000$ & $-3,02$ & $0,00305 * * *$ & 0,89 \\
\hline Switzerland & $-3,170$ & 1,590 & 4,82 & $<0,00001 * * *$ & $-0,140$ & $-2,04$ & $0,04395 * *$ & $-3,100$ & $-0,66$ & 0,50920 & 0,83 \\
\hline UK & $-0,250$ & 1,110 & 7,87 & $<0,00001 * * *$ & $-0,230$ & $-7,95$ & $<0,00001 * * *$ & 5,100 & 1,94 & $0,05493 *$ & 0,33 \\
\hline USA & $-2,310$ & $-9,000$ & 18,16 & $<0,00001 * * *$ & $-0,500$ & $-15,42$ & $<0,00001 * * *$ & 2,880 & $-2,43$ & $0,01645 * *$ & 0,91 \\
\hline
\end{tabular}

